\title{
Comparison of the Marginal Utility and Disease Burden of Hearing Loss and Other Chronic Diseases
}

\author{
Oh Deog Kwon', Se Young Jung ${ }^{2, *}$, Hwa Yeon Park'², Sue Kyoung Peak', Su Hwan Cho', Sang Jin Cho' \\ 'Department of Family Medicine, Seoul National University Hospital, Seoul, Korea \\ ${ }^{2}$ Department of Family Medicine, Seoul National University Bundang Hospital, Seoul National University College of Medicine, Seongnam, Korea
}

\begin{abstract}
Background: Compared with other chronic diseases, hearing loss is generally overlooked from the perspective of disease burden. However, hearing loss is emerging as an important issue in the current society. The objective of this study was to investigate disease burdens and marginal utilities associated with hearing loss and other chronic diseases.

Methods: This study analyzed the cross-sectional data of 32,986 participants aged 19 years and older who completed the Korea National Health and Nutrition Examination Surveys between 2009 and 2013. Additionally, this study used the pure tone audiometric test, European Quality of Life-Five Dimensions Questionnaire, and chronic disease status. The data were analyzed using a multiple linear regression method.

Results: The data of 23,297 people who underwent a pure tone audiogram and completed the European Quality of Life-Five Dimensions Questionnaire were used in this analysis. The marginal utility of hearing loss ranked fifth among nine chronic diseases. The estimated loss of quality-adjusted life years associated with hearing loss was -93.69 years per 100,000 people, which is similar to other chronic diseases.

Conclusion: This study assessed the marginal utilities and public burdens of hearing loss and eight chronic diseases in a South Korean population. Although the values may vary depending on country and race, this study may provide an indispensable foundation for more detailed studies on hearing loss.
\end{abstract}

Keywords: Hearing Loss; Quality-Adjusted Life Years; Chronic Disease; Global Burden of Disease

Received: March 3, 2017, Revised: August 9, 2017, Accepted: August 15, 2017

*Corresponding Author: Se Young Jung https://orcid.org/0000-0001-9946-8807

Tel: +82-31-787-7805, Fax: +82-31-787-4014, E-mail: imsyjung@gmail.com 


\section{INTRODUCTION}

As human life expectancy continues to increase worldwide, chronic diseases have become a public health burden in many developed countries. Public health policy-making depends on the use of comparative measures of the burdens of chronic diseases; therefore, societies must make difficult decisions regarding the public allocation of medical resources. The health-adjusted life year (HALY) is a measure of population health that enables the quantification of morbidity and mortality. ${ }^{1,2)}$ HALYs are useful for estimating the disease burden and comparing different diseases, populations, and economic analyses.

Average hearing thresholds are calculated at four frequencies- 0.5 , 1,2 , and $4 \mathrm{kHz}$ in decibel hearing levels (dBHLs) - and hearing loss is currently defined as an average hearing threshold of $>40 \mathrm{dBHL} .{ }^{3,4)}$ Hearing loss is a major health condition, affecting more than 278 million people worldwide at a moderate or severe level. The prevalence of hearing loss is increasing consequent to the aging population and the use of personal listening devices. ${ }^{5)}$ Hearing loss negatively affects social functioning, general quality of life, and interpersonal communication. ${ }^{6,7)}$ However, it is often neglected in comparison to other chronic diseases. ${ }^{8,9)}$

In cases of hearing loss, the quality of life is a more appropriate outcome than mortality and disability. ${ }^{10)}$ The quality-adjusted life year (QALY), a type of HALY, is a quantitative measurement of the quantity and quality of life. QALYs are representative values of an individual's health outcomes. Health is related to both the length and quality of life. Therefore, QALYs were developed to combine these attributes into a single, numeric, preference-based measures. Utility, an index of happiness or pleasure, is often used in economics and ranges from perfect health (1.0) to death (0). Marginal utility is the degree to which a oneunit change in a variable affects utility. In this study, we used the European Quality of Life-Five Dimensions Questionnaire (EQ-5D) to estimate the marginal utilities.

Several previous studies estimated the marginal utilities and burdens of various diseases, including hearing loss. However, all these studies assessed hearing loss using survey data, rather than a comprehensive measurement of hearing loss (e.g., pure tone audiogram). Furthermore, the studies did not derive data values from a representative population. ${ }^{11-13)}$ Accordingly, these studies lacked the essential elements needed to estimate the disease burden of hearing loss using QALY. Given the lack of existing comprehensive investigations, this study aimed to estimate the marginal utilities and QALY of common chronic diseases, including hearing loss. In this study, we used data from a representative sample of the South Korean population.

\section{METHODS}

\section{Study Population and Data Collection}

This study was based on a 5-year (2009-2013) dataset from the Korea National Health and Nutrition Examination Survey (KNHANES), which included an audiometric examination. The KNHANES is a cross-sectional and nationally representative survey that has been conducted since 1998 by the Korea Centers for Disease Control and Prevention and the Korean Ministry of Health and Welfare. ${ }^{14,15)}$ The participants were selected using proportional allocation-systemic sampling with multistage stratification. The survey team included an otolaryngologist, and nurse examiners who conducted health assessments using mobile devices, performed physical examinations, and interviewed subjects. The KNHANES comprises a nutritional survey, health examination survey, and health interview. Written informed consent was obtained from all participants before the survey.

\section{Health-Related Quality of Life Survey}

The health-related quality of life (HRQoL) was evaluated using the EQ$5 \mathrm{D}$, which is commonly favored for its brevity and international comparability. ${ }^{16)}$ All participants were asked to complete the Korean version of the EQ-5D. This test records three levels of self-reported problems (no problems, moderate problems, and extreme problems) in five dimensions (mobility, self-care, usual activities, pain/discomfort, and anxiety/depression). ${ }^{17-19)}$ The combinations of all possible dimensions yield $243\left(3^{5}\right)$ different health states. The EQ-5D score was calculated using the time trade-off method. ${ }^{20)}$ These scores range between -0.257 (worst health state) and 1.00 (perfect health state). ${ }^{18)}$ We used the EQ-5D score to analyze our QALY model.

\section{Audiometric Measurement and Definition of Hearing Loss}

A trained examiner used an automatic audiometer (SA-203; Entomed Diagnostic AB, Lena Nodin, Sweden) to measure the pure tone airconduction threshold in a double-walled, sound-proof booth. Automated testing was performed according to a modified Hughson-Westlake procedure. Each participant reacted by pushing a button when they heard a sound, and the results were automatically recorded. ${ }^{21)}$ The threshold average was calculated at four frequencies-0.5, 1, 2, and $4 \mathrm{kHz}-\mathrm{in} \mathrm{dBHLs}$. Hearing loss was defined as a threshold average $>40 \mathrm{dBHL}$ in the better ear, as stated by the World Health Organization. ${ }^{22)}$ The examination quality was verified by the Epidemiologic Survey Committee of the Korean Society of Otorhinolaryngology-Head and Neck Surgery.

\section{Sociodemographic Factors and Chronic Diseases}

Based on a previous study, this analysis included the following sociodemographic factors: age, smoking status (current smoker, exsmoker, or never-smoker), household income ( $>50 \%$ or $<50 \%$ ), education level (>high school or <middle school), occupation (white collar, blue collar, or unemployed), and living situation (living alone or not). ${ }^{23)}$ We regarded nine chronic diseases that might affect the HRQoL. These were hypertension, diabetes mellitus, dyslipidemia, stroke, myocardial infarction or ischemic heart disease, osteoarthritis or rheumatoid arthritis, asthma, obesity (body mass index $>30 \mathrm{~kg} / \mathrm{m}^{2}$ ), and hearing loss. All variables were included in a multiple linear regression analysis. 


\section{Statistical Analysis}

Our study included participants who underwent a pure tone audiogram examination and completed the EQ-5D questionnaire. We conducted a multiple linear regression analysis to estimate the coefficients of hearing loss and chronic diseases based on the EQ-5D scores. These regression coefficients were considered as the marginal utilities. We used the following equation to calculate the QALY loss per 100,000

Table 1. Baseline demographic characteristics of participants according to the presence of hearing loss

\begin{tabular}{|c|c|c|c|c|}
\hline Characteristic & $\begin{array}{l}\text { Normal } \\
\text { group }\end{array}$ & $\begin{array}{l}\text { Hearing loss } \\
\text { group* }\end{array}$ & Total & P-value ${ }^{\dagger}$ \\
\hline Age $(y)$ & & & & $<0.01$ \\
\hline $19-29$ & 2,431 & 2 & 2,433 & \\
\hline 30-39 & 3,712 & 8 & 3,720 & \\
\hline $40-49$ & 4,586 & 26 & 4,612 & \\
\hline $50-59$ & 4,608 & 95 & 4,703 & \\
\hline $60-69$ & 3,853 & 359 & 4,212 & \\
\hline $70-79$ & 2,420 & 644 & 3,064 & \\
\hline$\geq 80$ & 280 & 273 & 553 & \\
\hline Sex & & & & $<0.01$ \\
\hline Men & 9,207 & 756 & 9,963 & \\
\hline Women & 12,683 & 651 & 13,334 & \\
\hline Education & & & & $<0.01$ \\
\hline sElementary school & 5,188 & 956 & 6,144 & \\
\hline$\leq$ Middle school & 2,481 & 190 & 2,671 & \\
\hline$\leq$ High school & 7,664 & 192 & 7,856 & \\
\hline$\geq$ Graduate school & 6,544 & 66 & 6,610 & \\
\hline Occupation & & & & $<0.01$ \\
\hline White collar & 7,383 & 77 & 7,460 & \\
\hline Blue collar & 5,721 & 421 & 6,142 & \\
\hline Unemployed & 8,717 & 906 & 9,623 & \\
\hline Household income & & & & $<0.01$ \\
\hline Lowest quantile & 3,850 & 735 & 4,585 & \\
\hline Second quantile & 5,533 & 325 & 5,858 & \\
\hline Third quantile & 6,045 & 190 & 6,235 & \\
\hline Highest quantile & 6,248 & 147 & 6,395 & \\
\hline Smoking status & & & & $<0.01$ \\
\hline Non-smoker & 13,620 & 702 & 14,322 & \\
\hline Ex-smoker & 3,322 & 371 & 3,693 & \\
\hline Current smoker & 4,948 & 334 & 5,282 & \\
\hline Marital status & & & & $<0.01$ \\
\hline Married & 19,029 & 1,393 & 20,422 & \\
\hline Single & 2,850 & 14 & 2,864 & \\
\hline
\end{tabular}

Definition of white collar: worker who performs semi-professional, office, or salescoordination tasks. Definition of blue collar: worker who performs non-agricultural manual labor.

*Hearing loss was defined as a moderate to severe grade on the World Health Organization hearing loss classification. ${ }^{\dagger}$ Analyzed using chi-square tests. people using the estimated marginal utilities for each of the chronic diseases and hearing loss. ${ }^{12,13,24-26)}$

100,000 people annual QALY loss=marginal utility $\times 100,000$ people $\times$ 1 year×prevalence

We obtained data on the prevalence of hearing loss and chronic diseases among all participants in the 2009-2013 KNHANES. ${ }^{14)}$ Additionally, we applied the same analysis to people aged 55 years and older to estimate differences in the disease burden in an elderly population. For all data samples, survey sample weights were used to generate nationally representative results. Statistical analyses were conducted using STATA ver. 14.0 (Stata Corp., College Station, TX, USA).

\section{RESULTS}

A total of 23,297 participants were included in the marginal utility analysis (Table 1). The participants had a mean age (standard error) of 46.31 (0.20) years and mean EQ-5D index of 0.947 (0.001). A flowchart of the analysis is provided in Figure 1.

Table 2. Marginal utilities of hearing loss and other chronic diseases

\begin{tabular}{lccc}
\hline \multicolumn{1}{c}{ Chronic diseases } & $\begin{array}{c}\text { Marginal } \\
\text { utilities }\end{array}$ & $\begin{array}{c}\text { 95\% } \\
\text { confidence interval }\end{array}$ & P-value* \\
\hline Hearing loss & -0.0224 & -0.0363 to -0.0086 & $<0.01$ \\
Hypertension & -0.0025 & -0.0093 to 0.0043 & 0.472 \\
Diabetes & -0.0083 & -0.0149 to -0.0017 & 0.013 \\
Dyslipidemia & -0.0138 & -0.0215 to -0.0060 & $<0.01$ \\
Arthritis (osteoarthritis, & -0.0692 & -0.0780 to -0.0603 & $<0.01$ \\
$\quad$ rheumatoid arthritis) & & & \\
Stroke & -0.0579 & -0.0779 to -0.0379 & $<0.01$ \\
Ischemic heart disease & -0.0355 & -0.0549 to -0.0161 & $<0.01$ \\
Obesity & -0.0119 & -0.0219 to -0.0018 & 0.021 \\
Asthma & -0.0394 & -0.0553 to -0.0235 & $<0.01$ \\
\hline
\end{tabular}

The adjusted factors were age, sex, smoking status, household income, education, occupation, marital status, hypertension, diabetes, dyslipidemia, osteoarthritis or rheumatoid arthritis, stroke, ischemic heart disease, obesity, and asthma. Hearing loss was defined as a moderate to severe grade on the World Health Organization hearing loss classification. Hypertension was defined as a systolic blood pressure $>140 \mathrm{~mm} \mathrm{Hg}$ or diastolic blood pressure $>90 \mathrm{~mm} \mathrm{Hg}$ or diagnosis by a physician. Diabetes was defined as a glycated hemoglobin level $>6.5 \%$ or medication for diabetes or diagnosis by a physician. Dyslipidemia was defined as a total cholesterol level $>240 \mathrm{mg} / \mathrm{dL}$ or diagnosis by a physician. Obesity was defined as a body mass index of $\geq 30 \mathrm{~kg} / \mathrm{m}^{2}$. Other chronic diseases were defined as diagnosed or recognized by a physician. Marginal utilities were weighted to the Korean standard population $>19$ years of age.

*Analyzed using the multiple linear regression method.

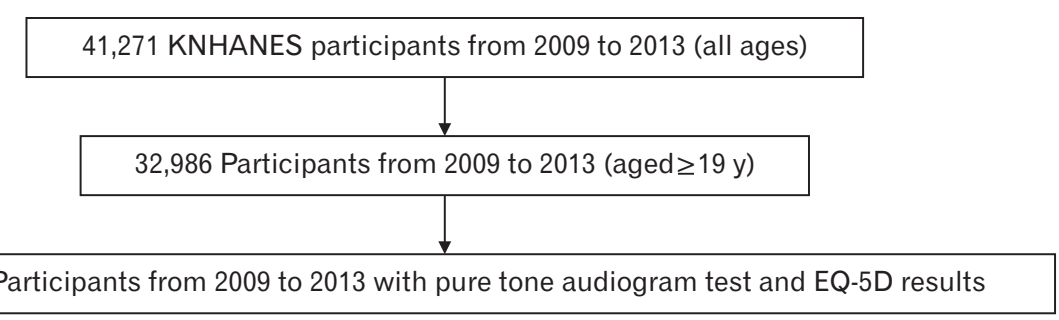

23,297 Participants from 2009 to 2013 with pure tone audiogram test and EQ-5D results
Figure 1. Flowchart of the number of included participants. KNHANES, Korean National Health and Nutrition Examination Survey; EQ$5 D$, European Quality of Life-Five Dimensions Questionnaire. 
The marginal utility for hearing loss, -0.0224 (95\% confidence interval, -0.0363 to -0.0086 ), was the fifth highest value on the list of chronic diseases. Detailed marginal utilities are provided in Table 2 and Figure 2. The prevalence of hearing loss in the South Korean population was 4.18\%. The measured loss of QALY for hearing loss was -93.69 per year per 100,000 people; again, this was the fifth highest value on the list of chronic diseases. Slight differences relative to other major chronic diseases (e.g., diabetes, dyslipidemia, asthma, and stroke) were observed. Hearing loss accounted for $5.23 \%$ of the total estimated QALY loss in the South Korean population. This proportion of QALY loss was similar in the elderly population ( $5.10 \%$ among people aged $\geq 55$ years). The prevalence of chronic diseases and yearly QALY losses are provided in Table 3 and Figures 3 and 4 . The results of participants aged $\geq 55$ years are provided in Tables 4 and 5 .

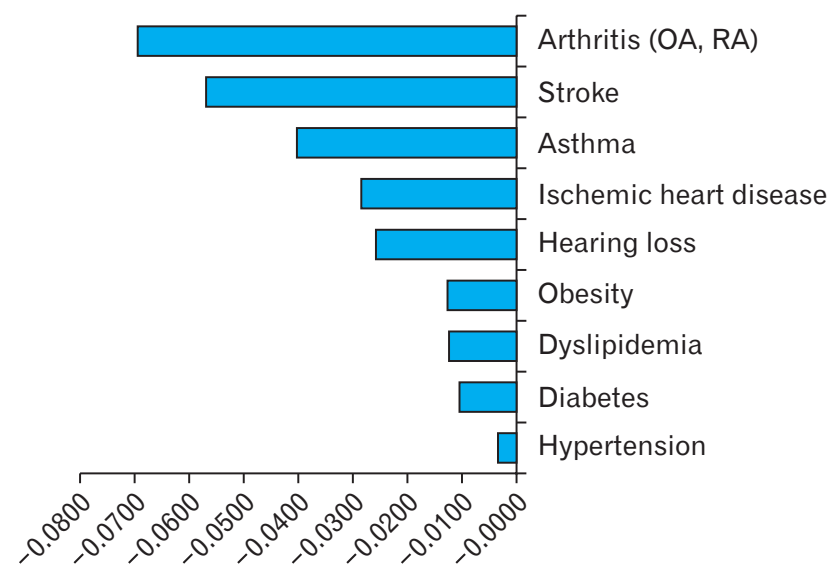

Figure 2. Marginal utilities for hearing loss and other chronic diseases. OA, osteoarthritis; RA, rheumatoid arthritis.

Table 3. Prevalence and estimated quality loss per 1 year associated with hearing loss and other chronic diseases

\begin{tabular}{lcc}
\hline \multicolumn{1}{c}{ Chronic diseases } & $\begin{array}{c}\text { Prevalence \% } \\
\text { (standard error) }\end{array}$ & $\begin{array}{c}\text { Quality-adjusted } \\
\text { life-year loss per year (\%) }\end{array}$ \\
\hline Hearing loss & $4.18(0.20)$ & $-93.69(5.23)$ \\
Hypertension & $18.84(0.49)$ & $-47.16(2.63)$ \\
Diabetes & $16.37(0.54)$ & $-136.54(7.62)$ \\
Dyslipidemia & $15.11(0.38)$ & $-208.05(11.61)$ \\
Arthritis (osteoarthritis, & $13.12(0.37)$ & $-907.08(50.64)$ \\
$\quad$ rheumatoid arthritis) & & \\
Stroke & $1.74(0.11)$ & $-100.51(5.61)$ \\
Ischemic heart disease & $2.56(0.15)$ & $-90.80(5.07)$ \\
Obesity & $4.98(0.27)$ & $-59.15(3.30)$ \\
Asthma & $3.76(0.21)$ & $-148.40(8.28)$ \\
\hline
\end{tabular}

Prevalence estimates were weighted to the Korean standard population $>19$ years of age. Hearing loss was defined as moderate-to-severe grade on the World Health Organization hearing loss classification. Hypertension was defined as systolic blood pressure of $>140 \mathrm{~mm} \mathrm{Hg}$ or diastolic blood pressure of $>90 \mathrm{~mm} \mathrm{Hg}$ or diagnosis by a physician. Diabetes was defined as hemoglobin A1c level of $>6.5 \%$ or medication for diabetes or diagnosis by a physician. Dyslipidemia was defined as total cholesterol level of $>240 \mathrm{mg} / \mathrm{dL}$ or diagnosis by a physician. Obesity was defined as a body mass index of $\geq 30 \mathrm{~kg} / \mathrm{m}^{2}$. Other chronic diseases were defined as diagnosed or recognized by a physician.

\section{DISCUSSION}

This study presents the estimated marginal utilities and prevalencebased QALY losses associated with hearing loss and eight other important chronic diseases among 23,297 participants in a representative Korean population. Using the KNHANES database, we analyzed the burdens of diseases that might have both substantial effects on HRQoL and prevalence rates in the population. The estimated marginal utilities are therefore an outcome measure that can be used to evaluate cost-effectiveness or make decisions regarding social assets.

In the present study, hearing loss had the fifth highest marginal utility among nine chronic diseases. This result indicates that hearing loss more strongly affects an individual's HRQoL than some other major chronic diseases. In addition, our use of nationally representative data allowed us to compare the public health burden of hearing loss with those of eight other chronic diseases in a nationally representative South Korean cohort.

The prevalence of hearing loss, $4.18 \%$, received an intermediate

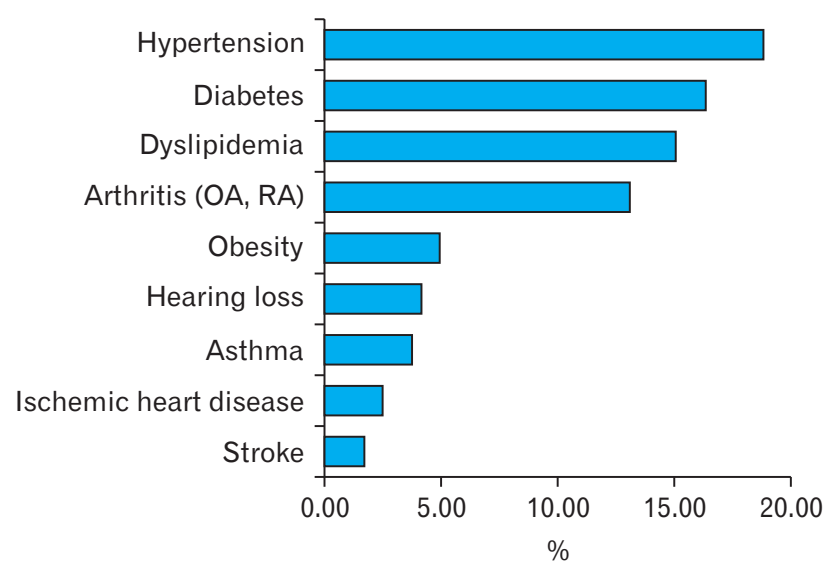

Figure 3. Prevalence rates of hearing loss and other chronic diseases. OA, osteoarthritis; RA, rheumatoid arthritis.

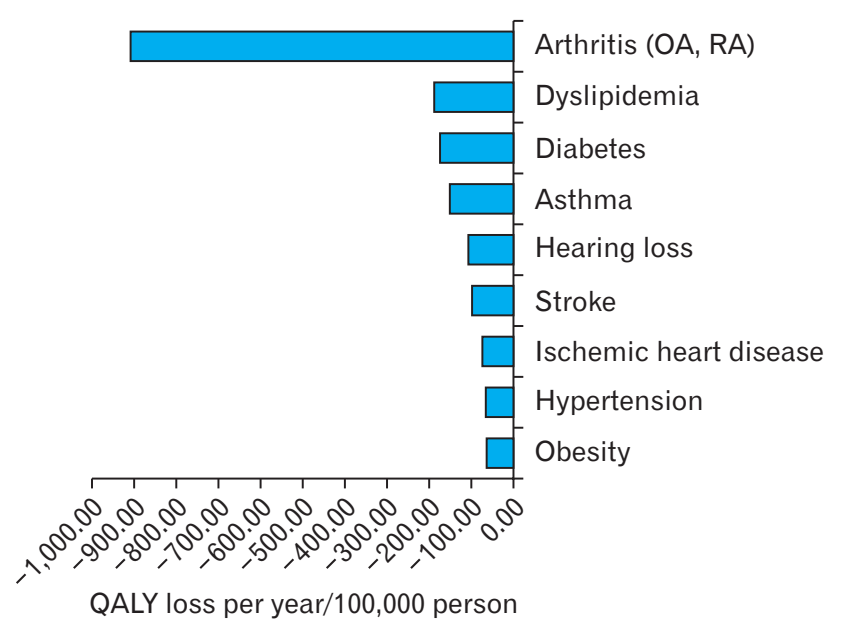

Figure 4. QALY losses associated with hearing loss and other chronic diseases. OA, osteoarthritis; RA, rheumatoid arthritis; QALY, quality-adjusted life-year. 
Table 4. Marginal utilities of hearing loss and other chronic diseases in the population aged $\geq 55$ years

\begin{tabular}{lccc}
\hline \multicolumn{1}{c}{ Chronic diseases } & $\begin{array}{c}\text { Marginal } \\
\text { utilities }\end{array}$ & $\begin{array}{c}\text { 95\% } \\
\text { confidence interval }\end{array}$ & P-value* \\
\hline Hearing loss & -0.0169 & -0.0327 to -0.0012 & 0.035 \\
Hypertension & -0.0017 & -0.0097 to 0.0064 & 0.686 \\
Diabetes & -0.0074 & -0.0166 to 0.0019 & 0.12 \\
Dyslipidemia & -0.0100 & -0.0198 to -0.0002 & 0.045 \\
$\begin{array}{l}\text { Arthritis (osteoarthritis, } \\
\quad \text { heumatoid arthritis) }\end{array}$ & -0.0746 & -0.0857 to -0.0636 & $<0.01$ \\
$\quad$ Stroke & -0.0635 & -0.0878 to -0.0392 & $<0.01$ \\
Ischemic heart disease & -0.0410 & -0.0663 to -0.0157 & $<0.01$ \\
Obesity & -0.0140 & -0.0339 to 0.0060 & 0.169 \\
Asthma & -0.0494 & -0.0774 to -0.0215 & $<0.01$ \\
\hline
\end{tabular}

The adjusted factors were age, sex, smoking status, household income, education, occupation, marital status, hypertension, diabetes, dyslipidemia, osteoarthritis or rheumatoid arthritis, stroke, ischemic heart disease, obesity, and asthma. Hearing loss was defined as moderate-to-severe grade on the World Health Organization hearing loss classification. Hypertension was defined as systolic blood pressure of $>140 \mathrm{~mm} \mathrm{Hg}$ or diastolic blood pressure of $>90 \mathrm{~mm} \mathrm{Hg}$ or diagnosis by a physician. Diabetes was defined as hemoglobin A1c level of $>6.5 \%$ or medication for diabetes or diagnosis by a physician. Dyslipidemia was defined as total cholesterol level of $>240 \mathrm{mg} / \mathrm{dL}$ or diagnosis by a physician. Obesity was defined as a body mass index of $\geq 30 \mathrm{~kg} / \mathrm{m}^{2}$. Other chronic diseases were defined as diagnosed or recognized by a physician. Marginal utilities were weighted to the Korean standard population aged $>19$ years.

*Analyzed using multiple linear regression method.

ranking among all evaluated chronic diseases. The value of the estimated yearly QALY loss for hearing loss was similar to those of diabetes and asthma and higher than those of stroke, ischemic heart disease, hypertension, and obesity. The proportion of the total estimated yearly QALY loss in our population was similar to that in an aged population. This finding emphasizes that hearing loss is an important issue for people of all ages. Accordingly, national health authorities should pay close attention to hearing loss.

Historically, calculations of the public health burden of hearing loss have yielded values as high as those for other chronic diseases, consistent with the findings of the present study. A similar study from United States used the International Classification of Diseases, Ninth Revision (ICD-9) to analyze 38,768 participants. ${ }^{11)}$ The results revealed that hearing loss had a higher marginal utility than arthritis, stroke, obesity, ischemic heart disease, diabetes, hypertension, and asthma. Additionally, the marginal utility of hearing loss was similar to that of dyslipidemia. In a study from the United Kingdom that used the ICD-9 to analyze 79,522 participants, the results demonstrated that hearing loss had a higher marginal utility than arthritis, stroke, ischemic heart disease, obesity, diabetes, asthma, and hypertension. ${ }^{27)}$ However, marginal utility of hearing loss was lower than that of dyslipidemia.

In a study from Finland that used the Diagnostic and Statistical Manual of Mental Disorders, 4th edition to evaluate 6,681 participants, the QALY loss associated with hearing loss was similar to that associated with ischemic heart disease and asthma but lower than that associated with arthritis, hypertension, stroke, and diabetes. ${ }^{12)}$ In a Dutch study that used the disability-adjusted life-years model and defined
Table 5. Prevalence and estimated quality loss per one year of hearing loss and chronic diseases in the population aged $\geq 55$ years

\begin{tabular}{lcc}
\hline \multicolumn{1}{c}{ Chronic diseases } & $\begin{array}{c}\text { Prevalence \% } \\
\text { (standard error) }\end{array}$ & $\begin{array}{c}\text { Quality-adjusted } \\
\text { life-year loss per year (\%) }\end{array}$ \\
\hline Hearing loss & $11.37(0.49)$ & $-192.50(5.10)$ \\
Hypertension & $42.33(0.86)$ & $-70.18(1.86)$ \\
Diabetes & $31.75(0.90)$ & $-233.74(6.19)$ \\
Dyslipidemia & $24.93(0.70)$ & $-249.41(6.61)$ \\
Arthritis (osteoarthritis, & $29.53(0.68)$ & $-2,203.54(58.38)$ \\
$\quad$ rheumatoid arthritis) & & \\
Stroke & $4.12(0.30)$ & $-261.58(6.93)$ \\
Ischemic heart disease & $5.83(0.35)$ & $-239.33(6.34)$ \\
Obesity & $3.65(0.29)$ & $-51.03(1.35)$ \\
Asthma & $5.52(0.36)$ & $-272.83(7.23)$ \\
\hline
\end{tabular}

Prevalence estimates were weighted to the Korean standard population $>19$ years of age. Hearing loss was defined as moderate-to-severe grade on the World Health Organization hearing loss classification. Hypertension was defined as systolic blood pressure of $>140 \mathrm{~mm} \mathrm{Hg}$ or diastolic blood pressure of $>90 \mathrm{~mm} \mathrm{Hg}$ or diagnosis by a physician. Diabetes was defined as $\mathrm{HbA} 1 \mathrm{C}$ level of $>6.5 \%$ or medication for diabetes or diagnosis by a physician. Dyslipidemia was defined as total cholesterol level of $>240 \mathrm{mg} / \mathrm{dL}$ or diagnosis by a physician. Obesity was defined as a body mass index of $\geq 30 \mathrm{~kg} / \mathrm{m}^{2}$. Other chronic diseases were defined as diagnosed or recognized by a physician.

diseases according to the ICD-9 diagnostic codes, the burden of hearing loss ranked ninth among 48 diseases, after ischemic heart disease, anxiety disorders, cerebrovascular disease, visual impairments, chronic lung disease, alcohol dependence, lung cancer, and depression. ${ }^{28)}$ In that study, the disability-adjusted life-years were estimated from mortality and morbidity data. When using disability-adjusted life-years based on morbidity alone, hearing loss ranked sixth among 45 diseases in the Dutch population, after anxiety disorder, visual impairment, alcohol dependence, depression, and chronic lung disease.

Historically, marginal utilities for hearing loss are rare in the literature, especially for hearing loss diagnosed via pure tone audiography. This study may provide a basis for future studies of hearing loss-related cost effectiveness. Unlike previous studies, the present study was based on a government-facilitated national survey and examination of a large number of representative participants. The resulting dataset has a low rate of missing values and a highly accurate definition of hearing loss based on pure tone audiogram data. This feature is a major strength of the present study. Another strength of this study was the use of the South Korean version of the preference-based method, ${ }^{18)}$ which differs across countries and cultures, ${ }^{11,27)}$ to derive the EQ-5D index.

However, this study also had several limitations. First, the EQ-5D index score has a ceiling effect. As many as $50 \%-65 \%$ of people in the general population reported a maximum value on the EQ-5D. These findings imply that the EQ-5D may not be sensitive for mild health conditions. Second, the KNHANES did not include hospitalized participants. Additionally, we excluded participants without hearing loss or EQ-5D data. Therefore, the results of this study are not applicable to hospitalized patients. Third, detailed marginal utilities and QALY loss vary among countries because of differences in culture, socio-eco- 
nomic backgrounds, eating habits, and lifestyles. Therefore, the applicability of our results to other races and countries is limited. Fourth, chronic diseases were defined using a health interview survey. Therefore, the exact numbers of cases may have been underestimated.

In conclusion, the present study has estimated the marginal utilities and burdens of nine chronic diseases, including hearing loss. As this study compared hearing loss with other chronic diseases, the findings provide a framework for future studies of the burden of hearing loss.

\section{CONFLICT OF INTEREST}

No potential conflict of interest relevant to this article was reported.

\section{REFERENCES}

1. Gold MR, Stevenson D, Fryback DG. HALYS and QALYS and DALYS, Oh My: similarities and differences in summary measures of population Health. Annu Rev Public Health 2002;23:115-34.

2. GBD 2013 Risk Factors Collaborators, Forouzanfar MH, Alexander L, Anderson HR, Bachman VF, Biryukov S, et al. Global, regional, and national comparative risk assessment of 79 behavioural, environmental and occupational, and metabolic risks or clusters of risks in 188 countries, 1990-2013: a systematic analysis for the Global Burden of Disease Study 2013. Lancet 2015;386:2287-323.

3. Mathers C, Smith A, Concha M. Global burden of hearing loss in the year 2000. Glob Burd Dis 2000;18:1-30.

4. Mackenzie I, Smith A. Deafness: the neglected and hidden disability. Ann Trop Med Parasitol 2009;103:565-71.

5. Agrawal Y, Platz EA, Niparko JK. Prevalence of hearing loss and differences by demographic characteristics among US adults: data from the National Health and Nutrition Examination Survey, 1999-2004. Arch Intern Med 2008;168:1522-30.

6. Kotby MN, Tawfik S, Aziz A, Taha H. Public health impact of hearing impairment and disability. Folia Phoniatr Logop 2008;60:58-63.

7. Mason A, Mason M. Psychologic impact of deafness on the child and adolescent. Prim Care 2007;34:407-26.

8. Arlinger S. Negative consequences of uncorrected hearing loss: a review. Int J Audiol 2003;42 Suppl 2:2S17-20.

9. Ock M, Han JW, Lee JY, Kim SH, Jo MW. Estimating quality-adjusted life-year loss due to noncommunicable diseases in Korean adults through to the year 2040. Value Health 2015;18:61-6.

10. Williams A. Calculating the global burden of disease: time for a strategic reappraisal? Health Econ 1999;8:1-8.

11. Sullivan PW, Ghushchyan V. Preference-Based EQ-5D index scores for chronic conditions in the United States. Med Decis Making 2006;26: 410-20.

12. Saarni SI, Harkanen T, Sintonen H, Suvisaari J, Koskinen S, Aromaa A, et al. The impact of 29 chronic conditions on health-related quality of life: a general population survey in Finland using 15D and EQ-5D. Qual Life Res 2006;15:1403-14.

13. Saarni SI, Suvisaari J, Sintonen H, Koskinen S, Harkanen T, Lonnqvist J. The health-related quality-of-life impact of chronic conditions varied with age in general population. J Clin Epidemiol 2007;60:1288-97.

14. Kweon S, Kim Y, Jang MJ, Kim Y, Kim K, Choi S, et al. Data resource profile: the Korea National Health and Nutrition Examination Survey (KNHANES). Int J Epidemiol 2014;43:69-77.

15. Kim Y, Park S, Kim NS, Lee BK. Inappropriate survey design analysis of the Korean National Health and Nutrition Examination Survey may produce biased results. J Prev Med Public Health 2013;46:96-104.

16. Rasanen P, Roine E, Sintonen H, Semberg-Konttinen V, Ryynanen OP, Roine R. Use of quality-adjusted life years for the estimation of effectiveness of health care: a systematic literature review. Int J Technol Assess Health Care 2006;22:235-41.

17. EuroQol Group. EuroQol: a new facility for the measurement of health-related quality of life. Health Policy 1990;16:199-208.

18. Lee YK, Nam HS, Chuang LH, Kim KY, Yang HK, Kwon IS, et al. South Korean time trade-off values for EQ-5D health states: modeling with observed values for 101 health states. Value Health 2009;12:1187-93.

19. Kim MH, Cho YS, Uhm WS, Kim S, Bae SC. Cross-cultural adaptation and validation of the Korean version of the EQ-5D in patients with rheumatic diseases. Qual Life Res 2005;14:1401-6.

20. Nam H, Kim K, Kwon S, Koh K, Poul K. EQ-5D Korean valuation study using time trade off method. Cheongju: Korea Centers for Disease Control and Prevention; 2007.

21. Mahomed F, Swanepoel de W, Eikelboom RH, Soer M. Validity of automated threshold audiometry: a systematic review and meta-analysis. Ear Hear 2013;34:745-52.

22. World Health Organization. Prevention of deafness and hearing impaired grades of hearing impairment [Internet]. Geneva: World Health Organization [cited 2017 Jan 20]. Available from: http://www.who.int/ whr/2002/chapter4/en/index8.html.

23. Park SJ, Ahn S, Woo SJ, Park KH. Extent of exacerbation of chronic health conditions by visual impairment in terms of health-related quality of life. JAMA Ophthalmol 2015;133:1267-75.

24. Fernandez A, Saameno JA, Pinto-Meza A, Luciano JV, Autonell J, Palao $\mathrm{D}$, et al. Burden of chronic physical conditions and mental disorders in primary care. Br J Psychiatry 2010;196:302-9.

25. Park SJ, Ahn S, Park KH. Burden of visual impairment and chronic diseases. JAMA Ophthalmol 2016;134:778-84.

26. Saarni SI, Suvisaari J, Sintonen H, Pirkola S, Koskinen S, Aromaa A, et al. Impact of psychiatric disorders on health-related quality of life: general population survey. Br J Psychiatry 2007;190:326-32.

27. Sullivan PW, Slejko JF, Sculpher MJ, Ghushchyan V. Catalogue of EQ5D scores for the United Kingdom. Med Decis Making 2011;31:800-4.

28. Melse JM, Essink-Bot ML, Kramers PG, Hoeymans N. A national burden of disease calculation: Dutch disability-adjusted life-years. Dutch Burden of Disease Group. Am J Public Health 2000;90:1241-7. 